\title{
Mammomonogamus laryngeus: an unusual cause of acute and chronic cough in the Caribbean area
}

\section{To the Editor:}

Mammomonogamus spp. and Syngamus spp. are nematodes in the Syngamidae family most often found in tropical environments. The parasites infest the respiratory tract of animals such as cattle, goats and sheep but human infestation is rare. Mammomonogamus spp. parasitise the respiratory tract and are responsible for respiratory symptoms dominated by coughing [1]. Approximately 100 cases have been described in the literature, nearly half of which came from the Caribbean [1-3]. In Martinique (a French overseas territory), the description of the parasite was made in the 1950s, and the largest series was published there $[2,3]$. Despite the improvement in living conditions since the 1980s, human infestation by Mammomonogamus spp. persists in Martinique.

The objective of this retrospective and descriptive study is to describe the clinical, biological and radiological characteristics of patients with mammomonogamosis.

Cases of mammomonogamosis were identified from records of the Pneumology Department of the Martinique teaching hospitals between January 1, 2008 and August 31, 2020. These were patients who underwent bronchial fibroscopy and in whom endobronchial Mammomonogamus laryngeus worm were found (figure 1).

Patients usually had a consultation with a pneumologist before the examination was performed. Data collection concerned age, sex, reason for consultation, biological abnormalities, radiological abnormalities, treatment and patient's evolution. Subjects provided consent for the image to be used for publication purposes.

During the period from January 1, 2008 to August 31, 2020, 12 patients were diagnosed with mammomonogamosis at the Teaching Hospital Martinique, 10 of whom were women. The average age of the patients was $36 \pm 13$ years. Cough was the characteristic symptom in all cases, mainly dry cough. In one case, the cough was accompanied by haemoptysis. The duration of symptoms before diagnosis varied from 10 days to $>6$ months. In addition to coughing, one patient presented with digestive disorders such as vomiting and weight loss (loss of $10 \%$ body weight). Another patient presented with a long-term febrile condition.

On thoracic imaging, three patients presented with pulmonary infiltrate-type abnormalities. Imaging was normal in the other cases.

Biologically, two patients presented with blood hypereosinophilia: $1.04 \times 10^{9} \cdot \mathrm{L}^{-1}(9.2 \%)$ and $0.76 \times 10^{9} \cdot \mathrm{L}^{-1}$ (8.5\%). Over 10 patients had eosinophilia under $0.5 \times 10^{9} \cdot \mathrm{L}^{-1}$. The worms were detected during bronchial endoscopy, usually as a pair of worms intertwined. They were removed with the forceps (1-4 pairs).

The patients then benefited from an antiparasitic treatment, either with albendazole $400 \mathrm{mg}^{-\mathrm{day}^{-1}}$ for 10 days or ivermectin according to the weight in a renewed dose 15 days later. The evolution is often marked by the disappearance of symptoms from the third day of treatment. None of the patients relapsed.

@ERSpublications

Mammomonogamus is an unusual cause of chronic cough found in the Caribbean region. The region is very popular with tourists. There is interest in thinking about a cough that cannot be explained in any patient who has stayed in this region. https://bit.ly/3qnemv9

Cite this article as: Agossou M, Jean-Baptiste S, Ehret N, et al. Mammomonogamus laryngeus: an unusual cause of acute and chronic cough in the Caribbean area. ERJ Open Res 2021; 7: 00814-2020 [https://doi.org/10.1183/23120541.00814-2020]. 
FIGURE 1 Mammomonogamus worm in the bronchus.

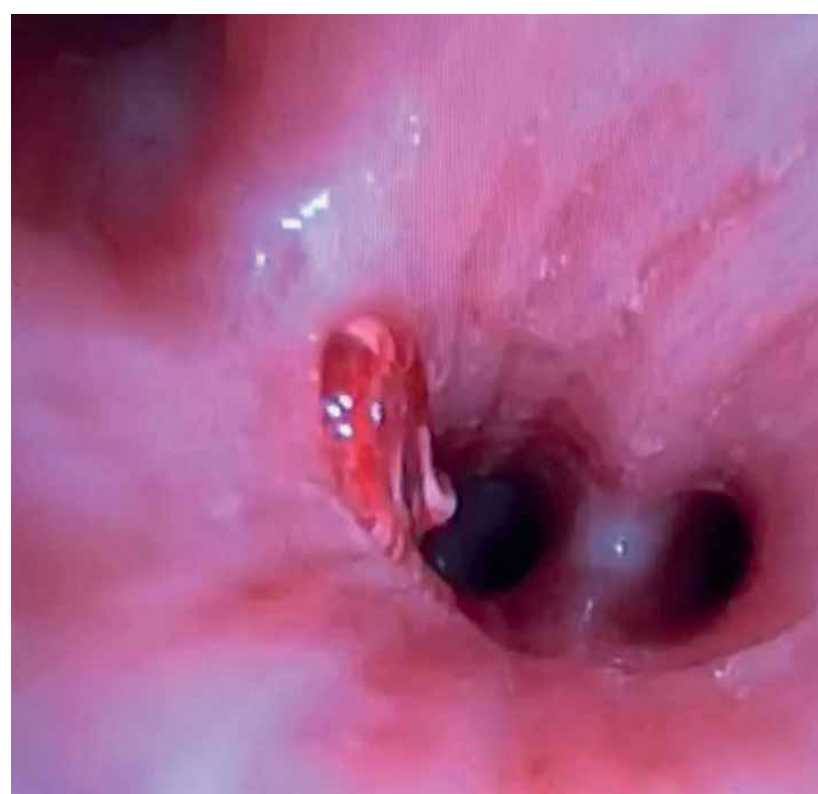

Mammomonogamosis is a parasitosis found in tropical areas. It most often affects animals such as cattle, goats, sheep or feline species. Human involvement is rare but persists in some areas. About a hundred cases have been described in the literature, most from the Caribbean and Latin America, [1, 4, 5], but cases have also been described in Asia [6,7]. This parasitosis persists in Martinique where the largest series was described by Mornex et al. [3] in the 1980s [2], despite the improvement in living conditions of the population.

In our report, mammomonogamosis mainly affects young women. This sex difference is not reported in the literature. We have no explanation to date for this female predominance other than sampling fluctuation.

The main symptom remains a dry irritant cough with usually normal imaging [1, 8-10], but chest computed tomography can show ground-glass type abnormalities or condensations on the lung.

The endoscopy makes it possible to image worms of Mammomonogamus laryngeus (figure 1).

While nearly half of the cases have been described in people native to Martinique, tourists can also contract mammomonogamosis, and many cases have been diagnosed after their return to their country of origin $[1,11]$. This unusual situation can lead to underdiagnosis. The Caribbean is an important tourist destination, and it is imperative that a diagnosis is sought in cases of chronic unexplained cough in patients returning from an endemic area.

Moustapha Agossou ${ }^{1}$, Sandy Jean-Baptiste ${ }^{1}$, Ninon Ehret ${ }^{1}$, Nicole Desbois-Nogard ${ }^{2}$, Moustapha Drame ${ }^{3}$ and Nicolas Venissac ${ }^{4}$

${ }^{1}$ Dept of Respiratory care, CHU Martinique, Fort-de-France, Martinique. ${ }^{2}$ Parasitology-Mycology Laboratory, CHU Martinique, Fort-de-France, Martinique. ${ }^{3}$ Dept of Clinical Research and Innovation, CHU Martinique, Fort-de-France, Martinique. ${ }^{4}$ Dept of Thoracic Surgery, CHRU Lille, Lille, France.

Correspondence: Moustapha Agossou, Dept of Respiratory care, CHU Martinique, Route de Chateauboeuf, 97261 Fort-de-France, CEDEX, Martinique. E-mail: moustapha.agossou@chu-martinique.fr

Received: 25 Nov 2020 | Accepted: 16 Dec 2020

Conflict of interest: None declared.

\section{References}

1 Nosanchuk JS, Wade SE, Landolf M. Case report of and description of parasite in Mammomonogamus laryngeus (human syngamosis) infection. J Clin Microbiol 1995; 33: 998-1000.

2 Saint-Prix L. [Human syngamosis in Martinique]. Ann Parasitol Hum Comp 1950; 25: 235-236.

3 Mornex JF, Magdeleine J, De Thore J. [Human Syngamus (Mammonogonus nasicola) infestation as a cause of chronic cough in Martinique. 37 cases (author's transl)]. Nouv Presse Med 1980; 9: 3628. 
4 Castaño JC, Núñez FA, González MM, et al. [First case report of Mammomonogamus (Syngamus) laryngeus human infection in Colombia]. Biomed Rev Inst Nac Salud 2006; 26: 337-341.

5 Marques SMT, Quadros RM, Pilati C. Mammomonogamus laryngeus (Railliet, 1899) infection in buffaloes in Rio Grande do Sul, Brazil. Vet Parasitol 2005; 130: 241-243.

6 Van Aken D, Lagapa JT, Dargantes AP, et al. Mammomonogamus laryngeus (Railliet, 1899) infections in cattle in Mindanao, Philippines. Vet Parasitol 1996; 64: 329-332.

7 Foitová I, Koubková B, Barus V, et al. Presence and species identification of the gapeworm Mammomonogamus laryngeus (Railliet, 1899) (Syngamidae: Nematoda) in a semi-wild population of Sumatran orangutan (Pongo abelii) in Indonesia. Res Vet Sci 2008; 84: 232-236.

8 Pontes PA, Gadelha ME, Gregorio LC. Pathologic quiz case 2. Laryngeal syngamosis. Arch Otolaryngol Head Neck Surg 1993; 119: 570-571.

9 Gardiner CH, Schantz PM. Mammomonogamus infection in a human. Report of a case. Am J Trop Med Hyg 1983; 32: 995-997.

10 Timmons RF, Bowers RE, Price DL. Infection of the respiratory tract with Mammomanogamus (Syngamus) laryngeus: a new case in Largo, Florida, and a summary of previously reported cases. Am Rev Respir Dis 1983; 128: 566-569.

11 Angheben A, Gobbo M, Gobbi F, et al. Human syngamosis: an unusual cause of chronic cough in travellers. BMJ Case Rep 2009; 2009: bcr1220081305. 